\section{Apoio matricial e equipe de referência: uma metodologia para gestão do trabalho interdisciplinar em saúde}

\author{
Matrix support and reference team: a \\ methodology for interdisciplinary \\ health work management
}

\footnotetext{
${ }^{1}$ Faculdade de Ciência Médicas, Universidade Estadual de Campinas, Campinas, Brasil.

Correspondência G.W. S. Campos Departamento de Medicina Preventiva e Social, Faculdade de Ciência Médicas, Universidade Estadual de Campinas. Cidade Universitária Zeferino Vaz, C. P. 6111, Campinas, SP 13084-971, Brasil. gastaowagner@mpc.com.br
}

\begin{abstract}
The authors discuss a theoretical and conceptual management methodology based on reference teams and matrix support. Reference team is a structural organization intended to combine managerial power and interdisciplinary work. Matrix support changes the way traditional health systems work, with specialists organically linked to other teams who periodically require specialized consultation. Besides care support, there is another goal: to build new knowledge for each health professional through a continuing education process. The article analyzes the structural, political, cultural, theoretical, and subjective obstacles to this new model.
\end{abstract}

Health Management; Methodology; Epistemology
Gastão Wagner de Sousa Campos 1 Ana Carla Domitti 1

\section{Introdução}

Os conceitos de apoio matricial e equipe de referência foram propostos por Campos 1 dentro da linha de pesquisa voltada para a reforma das organizações e do trabalho em saúde. Posteriormente, essa metodologia de gestão do cuidado foi adotada em serviços de saúde mental ${ }^{2}$, de atenção básica e da área hospitalar do Sistema Único de Saúde (SUS) de Campinas, São Paulo, Brasil ${ }^{3}$. Algum tempo depois, alguns programas do Ministério da Saúde - Humaniza-SUS 4, Saúde Mental 5 e Atenção Básica/Saúde da Família 6 - também incorporaram essa perspectiva. Este trabalho objetiva descrever esses dois arranjos organizacionais, indicar conceitos e teorias sobre os quais se apóiam essa metodologia de trabalho, bem como identificar obstáculos epistemológicos e da estrutura dos serviços que essa alternativa propõe-se a enfrentar. Tal estudo servirá de elemento de base para apoiar pesquisas que avaliem limitações e potência dessa modalidade organizacional.

\section{O que é e como funcionam o apoio matricial e a equipe de referência}

O apoio matricial em saúde objetiva assegurar retaguarda especializada a equipes e profissionais encarregados da atenção a problemas de saúde. Trata-se de uma metodologia de trabalho 
complementar àquela prevista em sistemas hierarquizados, a saber: mecanismos de referência e contra-referência, protocolos e centros de regulação. O apoio matricial pretende oferecer tanto retaguarda assistencial quanto suporte técnicopedagógico às equipes de referência. Depende da construção compartilhada de diretrizes clínicas e sanitárias entre os componentes de uma equipe de referência e os especialistas que oferecem apoio matricial. Essas diretrizes devem prever critérios para acionar o apoio e definir o espectro de responsabilidade tanto dos diferentes integrantes da equipe de referência quanto dos apoiadores matriciais.

A equipe ou profissional de referência são aqueles que têm a responsabilidade pela condução de um caso individual, familiar ou comunitário. Objetiva ampliar as possibilidades de construção de vínculo entre profissionais e usuários 7 . O termo responsabilidade de condução refere-se à tarefa de encarregar-se da atenção ao longo do tempo, ou seja, de maneira longitudinal, à semelhança do preconizado para equipes de saúde da família na atenção básica ${ }^{8}$. O conceito de equipe de referência pressupõe a adoção de lógica análoga para profissionais que trabalhem em policlínicas ou hospitais, como é o caso de terapeutas ocupacionais, psiquiatras e psicólogos que trabalham em centros de apoio psicossocial; de infectologistas, enfermeiros e assistentes sociais no programa de DST/AIDS; de ortopedistas, cirurgiões e enfermeiros em departamentos de trauma etc.

Apoio matricial e equipe de referência são, ao mesmo tempo, arranjos organizacionais e uma metodologia para a gestão do trabalho em saúde, objetivando ampliar as possibilidades de realizar-se clínica ampliada e integração dialógica entre distintas especialidades e profissões. A composição da equipe de referência e a criação de especialidades em apoio matricial buscam criar possibilidades para operar-se com uma ampliação do trabalho clínico e do sanitário, já que se considera que nenhum especialista, de modo isolado, poderá assegurar uma abordagem integral. Essa metodologia pretende assegurar maior eficácia e eficiência ao trabalho em saúde, mas também investir na construção de autonomia dos usuários. Sua utilização como instrumento concreto e cotidiano pressupõe certo grau de reforma ou de transformação do modo como se organizam e funcionam serviços e sistemas de saúde. Isso indica a existência de dificuldades e obstáculos para a reorganização do trabalho em saúde a partir dessas diretrizes.

A equipe de referência é um rearranjo organizacional que busca deslocar o poder das profissões e corporações de especialistas, reforçan- do o poder de gestão da equipe interdisciplinar. Procura fazer coincidir a unidade de gestão que compõe as organizações de saúde com a unidade de produção interdisciplinar. No caso, a menor unidade organizacional passaria a ser a equipe de referência. A equipe de referência é composta por um conjunto de profissionais considerados essenciais para a condução de problemas de saúde dentro de certo campo de conhecimento. Dentro dessa lógica, a equipe de referência é composta por distintos especialistas e profissionais encarregados de intervir sobre um mesmo objeto - problema de saúde -, buscando atingir objetivos comuns e sendo responsáveis pela realização de um conjunto de tarefas, ainda que operando com diversos modos de intervenção. $\mathrm{O}$ máximo de poder delegado à equipe interdisciplinar. Não todo o poder, porque há o poder dos gestores e usuários, necessários para o cumprimento da função de coordenação, de integração e de avaliação do trabalho das distintas equipes de referência. Em organizações maiores, faz-se necessário a agregação de equipes de referência em departamentos estruturados dentro da mesma lógica: as unidades de produção seriam a agregação de um conjunto de equipes de referência e de apoiadores matriciais que compartilhem de um mesmo campo de intervenção.

A gestão do trabalho interdisciplinar em equipes de referência depende de uma série de instrumentos operacionais. Para que ocorra clara definição da responsabilidade sanitária e se ampliem as possibilidades de construção de vínculo, é fundamental valer-se da metodologia de adscrição de clientela à equipe de referência. No caso, cada equipe de referência terá um registro e um cadastro de casos sob sua responsabilidade. O manejo desse cadastro permitirá avaliação de risco e vulnerabilidade, identificando-se aqueles casos que mereceriam a elaboração de um projeto terapêutico singular, ou mesmo alteração da avaliação diagnóstica ou dos procedimentos de cuidado.

A equipe de referência manterá uma relação longitudinal no tempo com esse conjunto de usuários, para isso é fundamental que a inserção dos profissionais no serviço dê-se de modo horizontal, contratação como diaristas. A inserção vertical justificar-se-ia somente para aqueles profissionais em regime de plantão. Com essa metodologia, a equipe de referência permanece responsável pela condução dos casos inscritos em seu cadastro, mesmo quando algum tipo de apoio especializado foi acionado. Como a proposta de equipes de referência é extensiva aos hospitais, centros de referência, enfermarias, unidades de urgência ou de terapia intensiva, fica evidente que a adscrição de clientela em 
cada um desses casos terá uma temporalidade distinta daquela das equipes de saúde da família, em geral, mais longa. Um paciente em tratamento de AIDS deveria permanecer adscrito a uma equipe de referência de um centro especializado enquanto persistir seu problema; um outro em uma enfermaria permanecerá referido a determinada equipe enquanto durar seu tratamento no hospital.

O funcionamento dialógico e integrado da equipe de referência pressupõe tomá-la como um espaço coletivo, que discute casos clínicos, sanitários ou de gestão, e participa da vida da organização.

O apoiador matricial é um especialista que tem um núcleo de conhecimento e um perfil distinto daquele dos profissionais de referência, mas que pode agregar recursos de saber e mesmo contribuir com intervenções que aumentem a capacidade de resolver problemas de saúde da equipe primariamente responsável pelo caso. $\mathrm{O}$ apoio matricial procura construir e ativar espaço para comunicação ativa e para o compartilhamento de conhecimento entre profissionais de referência e apoiadores.

O apoio matricial busca personalizar os sistemas de referência e contra-referência, ao estimular e facilitar o contato direto entre referência encarregada do caso e especialista de apoio. Nesse sentido, essa metodologia altera o papel das Centrais de Regulação, reservando-lhe uma função na urgência, no zelo pelas normas e protocolos acordados e na divulgação do apoio disponível. A decisão sobre o acesso de um caso a um apoio especializado seria, em última instância, tomada de maneira interativa, entre profissional de referência e apoiador. $\mathrm{O}$ regulador à distância teria um papel de acompanhar e avaliar a pertinência dessas decisões e de tomá-las somente em situações de urgência, quando não haveria tempo para o estabelecimento de contato entre referência e apoio matricial.

Há duas maneiras básicas para o estabelecimento desse contato entre referências e apoiadores. Primeiro, mediante a combinação de encontros periódicos e regulares - a cada semana, quinzena ou mais espaçados - entre equipe de referência e apoiador matricial. Nesses encontros, objetiva-se discutir casos ou problemas de saúde selecionados pela equipe de referência e procura-se elaborar projetos terapêuticos e acordar linhas de intervenção para os vários profissionais envolvidos. Recomenda-se reservar algum tempo para diálogo sobre temas clínicos, de saúde coletiva ou de gestão do sistema. Segundo, além desses encontros, em casos imprevistos e urgentes, em que não seria recomendável aguardar a reunião regular, como na lógica dos sistemas hie- rarquizados, o profissional de referência aciona o apoio matricial, de preferência por meios diretos de comunicação personalizados, contato pessoal, eletrônico ou telefônico e não apenas por meio de encaminhamento impresso entregue ao paciente, solicitando-se algum tipo de intervenção ao apoiador. Nessas circunstâncias, é recomendável proceder-se a uma avaliação de risco para se acordar uma agenda possível.

O apoio matricial implica sempre a construção de um projeto terapêutico integrado, no entanto essa articulação entre equipe de referência e apoiadores pode desenvolver-se em três planos fundamentais:

a) atendimentos e intervenções conjuntas entre o especialista matricial e alguns profissionais da equipe de referência;

b) em situações que exijam atenção específica ao núcleo de saber do apoiador, este pode programar para si mesmo uma série de atendimentos ou de intervenções especializadas, mantendo contato com a equipe de referência, que não se descomprometeria com o caso, ao contrário, procuraria redefinir um padrão de seguimento complementar e compatível ao cuidado oferecido pelo apoiador diretamente ao paciente, ou à família ou à comunidade;

c) é possível ainda que o apoio restrinja-se à troca de conhecimento e de orientações entre equipe e apoiador; diálogo sobre alterações na avaliação do caso e mesmo reorientação de condutas antes adotadas, permanecendo, contudo, o caso sob cuidado da equipe de referência.

Essa dinâmica presta-se tanto para ordenar a relação entre os níveis hierárquicos do sistema quanto para facilitar a comunicação e integração de equipes de saúde da família e especialistas, ou mesmo entre distintas especialidades e profissões de saúde que trabalhem em um mesmo serviço, hospital ou centro de referência. Em Campinas foram criados Núcleos de Saúde Coletiva na atenção básica, que deveriam fornecer apoio matricial em saúde pública (vigilância, promoção, projetos de intervenção comunitários ou intersetoriais, avaliação e planejamento de programas etc.) para as equipes de saúde da família. Organizou-se também apoio em áreas clínicas como, saúde mental, nutrição e reabilitação física 9 .

O termo apoio matricial é composto por dois conceitos operadores. O segundo deles - matricial - indica uma mudança radical de posição do especialista em relação ao profissional que demanda seu apoio. Na teoria de sistemas de saúde, há o princípio da hierarquização 10 , em que se prevê uma diferença de autoridade entre quem encaminha um caso e quem o recebe; o nível primário dirige-se ao secundário e assim 
sucessivamente, havendo ainda uma transferência de responsabilidade quando do encaminhamento. Tratar-se-ia de relações do tipo vertical, em que a comunicação entre os níveis ocorre por meio de informes escritos - no caso, a planilha de referência -, apenas para transferir uma responsabilidade e receber algum informe ao final do procedimento - o formulário de contra-referência. Esse estilo de relação entre trabalhadores foi concebido pela administração clássica, induzindo sistemas burocráticos e pouco dinâmicos. Ao criticar esse modelo de gestão do trabalho, alguns teóricos sugeriram pensar-se as organizações como uma matriz 11, em que a inevitável departamentalização, que estipula uma linha de comando e de gestão vertical, induzindo uma fragmentação do processo de trabalho, poderia ter seus efeitos atenuados se fossem criadas ações horizontais que atingissem vários desses departamentos. Pensavam em projetos, comissões ou supervisores que atuassem de maneira horizontal, em vários departamentos, mas sem autoridade gerencial sobre as pessoas que constituem esses departamentos.

O termo matriz carrega vários sentidos; por um lado, em sua origem latina, significa o lugar onde se geram e se criam coisas; por outro, foi utilizado para indicar um conjunto de números que guardam relação entre si quer os analisemos na vertical, na horizontal ou em linhas transversais 12 . Pois bem, o emprego desse nome - matricial - indica essa possibilidade, a de sugerir que profissionais de referência e especialistas mantenham uma relação horizontal, e não apenas vertical como recomenda a tradição dos sistemas de saúde. Trata-se de uma tentativa de atenuar a rigidez dos sistemas de saúde quando planejados de maneira muito estrita segundo as diretrizes clássicas de hierarquização e regionalização 13 .

O primeiro termo - apoio - sugere uma maneira para operar-se essa relação horizontal mediante a construção de várias linhas de transversalidade, ou seja, sugere uma metodologia para ordenar essa relação entre referência e especialista não mais com base na autoridade, mas com base em procedimentos dialógicos. O termo foi retirado do método Paidéia ${ }^{14}$, que cria a figura do apoiador institucional e sugere que tanto na gestão do trabalho em equipe quanto na clínica, na saúde pública ou nos processos pedagógicos, a relação entre sujeitos com saberes, valores e papéis distintos pode ocorrer de maneira dialógica. No caso, o apoiador procura construir de maneira compartilhada com os outros interlocutores projetos de intervenção, valendo-se tanto de ofertas originárias de seu núcleo de conhecimento, de sua experiência e visão de mundo, quanto incorporando demandas trazidas pelo outro também em função de seu conhecimento, desejo, interesses e visão de mundo.

Procura-se criar espaços coletivos protegidos que permitam a interação dessas diferenças, buscando-se construir uma análise e uma interpretação sintética, bem como se acordando linhas de intervenção e distribuição de tarefas entre os vários sujeitos envolvidos no processo.

\section{Obstáculo estrutural}

Há obstáculos na própria maneira como as organizações vêm se estruturando, que conspiram contra esse modo interdisciplinar e dialógico de operar-se. Esses obstáculos precisam ser conhecidos, analisados e, quando possível, removidos ou enfraquecidos para que seja possível trabalhar-se com base em equipe interdisciplinar e sistemas de co-gestão.

O apoio matricial e a equipe de referência são metodologias de trabalho, modo para se realizar a gestão da atenção em saúde, mas são, ao mesmo tempo, arranjos organizacionais que buscam diminuir a fragmentação imposta ao processo de trabalho decorrente da especialização crescente em quase todas as áreas de conhecimento. Para que a interdisciplinaridade ocorra de fato e contribua para aumentar a eficácia das intervenções, é importante não somente se facilitar a comunicação entre distintos especialistas e profissionais 15 , como também montar um sistema que produza um compartilhamento sincrônico e diacrônico de responsabilidades pelos casos e pela ação prática e sistemática conforme cada projeto terapêutico específico. O papel de cada instância, de cada profissional, deve ficar bem claro. Alguém deve se responsabilizar pelo seguimento longitudinal e pela construção de uma lógica que procure integrar a contribuição dos vários serviços, departamentos e profissionais. Em geral, esse papel cabe a integrantes da equipe de referência. Com certeza, não é essa a tradição de funcionamento dos serviços de saúde.

Em Medicina e na saúde em geral houve uma crescente divisão do trabalho que dificulta a integração do processo de atenção e cuidado às pessoas, já que as distintas especialidades médicas e profissões de saúde definiram objetos de intervenção e campos de conhecimento sem grandes compromissos com a abordagem integral de processos saúde e doença concretos 16 .

Em decorrência dessa realidade vieram se estruturando organizações de saúde com elevado grau de departamentalização. Analisando a estrutura de duas organizações prototípicas da área da saúde - o hospital e o ambulatório - ve- 
rificamos que elas, em geral, dividem-se em departamentos ordenados segundo lógica das profissões e especialidades médicas 17. Estudiosos da administração têm identificado várias racionalidades que vêm sendo empregadas para dividir responsabilidades em organizações contemporâneas. Há organizações com departamentos ordenados segundo produtos - tipos de bens ou serviços produzidos -, outras de acordo com etapas do processo de trabalho ou ainda com a função de cada área da empresa, outras se dividem segundo a clientela a ser atendida, há também aquelas que se organizam segundo o território onde o trabalho se realiza 18.

Pois bem, em hospitais, ambulatórios e outros serviços de saúde tem predominado uma lógica que leva ao extremo a fragmentação do cuidado. Verifica-se na área da saúde que a construção de unidades de gestão obedece antes de tudo à lógica corporativa e das profissões. Esse fato é marcante em áreas voltadas para a assistência ao usuário, que se organizam em departamentos, diretorias ou coordenações recortadas segundo profissão ou especialidade médica 19 . Em áreas-meio, em geral, observa-se uma agregação maior, identificando-se unidades de gestão recortadas segundo funções: departamento de administração e finanças, lavanderia, nutrição e dietética, laboratório etc. ${ }^{20}$. No entanto, nos departamentos voltados diretamente para a atenção ao usuário, encontra-se departamento de enfermagem, de ortopedia, de psiquiatria, infectologia etc. Nesses serviços, há uma composição multiprofissional de pessoal, com baixo grau de coordenação, comunicação e integração entre as distintas especialidade e profissões. Até mesmo o desenho arquitetônico da maioria dos ambulatórios reflete essa lógica de ferro: uma sucessão de pequenas salas para consultório ou procedimentos que, de tão desconectados, bem poderiam funcionar em espaços geográficos distintos.

Essa estrutura cria dificuldades gerenciais extremas e constitui-se em um obstáculo estrutural à adoção do método de trabalho de apoio matricial. Um mesmo espaço de trabalho, uma enfermaria hospitalar, por exemplo, com responsabilidade sanitária, objetivos, métodos de trabalho e funções, todos muito bem definidos; quando a organização obedece a essa lógica de departamentos corporativos, não se constitui em uma única unidade de gestão. Ao contrário, essa mesma enfermaria tende a ser comandada por, no mínimo, meia dúzia de gerentes que não estão obrigados a se compor em colegiados ou a coordenar e integrar seus planos de trabalho. Em uma mesma enfermaria destinada à Psiquiatria, por exemplo, pode haver um comandante dos mé- dicos especialistas, o psiquiatra chefe; há outro chefe de enfermagem; outro comanda os psicólogos, outro os fisioterapeutas, outro a assistente social; a disciplina, regras para visitas, a limpeza e suprimento serão comandados por um outro chefe da área administrativa; e caso haja ainda casos clínicos complicados, o médico internista terá ainda um décimo diretor diferente.

Esse tipo de estrutura também contribui para diluir a responsabilidade sanitária sob os casos acompanhados. Há uma dupla fragmentação, do processo de trabalho e da unidade de gestão, que dificulta a identificação clara do responsável clínico, bem como torna quase impossível a integração comunicativa das abordagens diagnósticas e terapêuticas. Esse fenômeno está sendo denominado de obstáculo estrutural à prática de uma clínica ampliada, bem como do trabalho interdisciplinar. Valeria proceder-se maiores investigações para esclarecer o peso que esse tipo de obstáculo teria na tendência a custos crescentes, perda de eficácia e aumento da iatrogenia verificada em serviços de saúde 21 .

Não é lógico, parece pouco racional, mas assim vem funcionando há décadas na maioria dos serviços de saúde. Vem funcionando, porque a administração sanitária tem se utilizado de vários instrumentos para atenuar os efeitos negativos desses obstáculos estruturais. Entre os recursos gerenciais que se contrapõem a essa tendência, ressalta-se o papel integrador do corpo de enfermagem, que ainda que organizado de maneira vertical e paralela às demais profissões - daí advém o conceito utilizado de "corpo" -, espalha-se por todo o hospital, compensando, com seu zelo, a extrema fragmentação imposta pela circulação vertiginosa de especialistas entre usuários 22 . Outros recursos freqüentemente adotados para atenuar esse tipo de fragmentação são normas, sistemas de acreditação e protocolos que procuram padronizar condutas e definir fluxos por onde deveriam circular os pacientes 23 .

Essas tendências à descontinuidade e a fragmentação dos projetos terapêuticos acentuamse quando a intervenção depende de mais de um serviço integrante do sistema de saúde. O recurso gerencial utilizado para conectar esses pedaços são os sistemas de referência e contra-referência e os Centros de Regulação com seus protocolos e regulamentações. Alguns sistemas criam instâncias de decisão - gestão de caso - distanciadas do atendimento direto ao paciente: são os famosos reguladores a distância ou gerentes de casos 24 .

Que potência teria a reestruturação das organizações de saúde segundo equipes interdisciplinares apoiadas por especialistas matriciais? Há evidências teóricas de que contribuiria bastante para melhor definir os padrões de responsabili- 
dade sanitária, permitindo com isso o estabelecimento de programas com coeficiente de vínculo entre profissionais e usuários mais humanos e eficazes, além de criar espaço onde uma integração interdisciplinar seja possível, ainda que não automática ou de simples execução.

\section{Obstáculos decorrentes do excesso de demanda e da carência de recursos}

A implantação do SUS é parcial. Há evidências indicando que o volume de serviços oferecidos à população brasileira ainda é insuficiente 25 . De qualquer modo, reconhece-se que esses recursos poderiam ter um uso mais adequado e racional, caso ocorressem reordenações no modelo de gestão e de atenção ${ }^{26}$. Ressalte-se, nesse aspecto, o papel que a construção de uma rede básica com ampla cobertura populacional e capacidade de resolver problemas tem tido na viabilidade de sistemas nacionais de saúde 27. Entre outros arranjos, também o apoio matricial poder ser relevante para racionalizar o acesso e o uso de recursos especializados, alterando-se ainda a ordenação predominantemente multidisciplinar do sistema para uma outra mais consentânea com a interdisciplinaridade. Esse arranjo permite um uso racional de recursos, quando cria oportunidade para que um único especialista integre organicamente seu trabalho com o de várias equipes de referência. Por exemplo: um único clínico geral ou um fisioterapeuta poderia assegurar apoio matricial a várias (quatro, cinco, seis?) equipes especializadas em trauma e composta por cirurgiões, ortopedistas e enfermeiros, contribuindo tanto para a avaliação conjunta do estado clínico dos casos quanto para o controle de infecções pós-cirúrgicas ou de outras intercorrências clínicas. Com esse tipo de relação, no decorrer do tempo, a equipe de trauma iria incorporando em seu campo de conhecimento aspectos antes delegados aos clínicos ou fisioterapeutas, ampliando com isso sua capacidade de resolver problemas de saúde e indicando com mais sensibilidade e precisão os casos que necessitariam de apoio especializado.

Como o apoio é dinâmico e depende de relações interpessoais, esses especialistas como que passariam a fazer parte dessa meia dezena de equipes de trauma, possibilitando, em tese, uma ampliação da visão sobre o processo saúde, doença, intervenção, sem que haja uma diluição da responsabilidade sobre os casos. Também nesse aspecto esse obstáculo funciona como um empecilho para o apoio matricial, no entanto o apoio matricial é, ao mesmo tempo, uma maneira de reduzir a potência desse obstáculo.

\section{Obstáculo político e de comunicação}

As organizações de saúde têm a tradição de funcionar com concentração de poder: concentrado nos diretores, nos médicos e nos especialistas. O SUS introduziu a diretriz do controle social, no entanto a idéia de gestão compartilhada foca instâncias do sistema de saúde - conferências e conselhos em municípios, estados e união - e não necessariamente internas aos serviços ou programas 28 . As criações de espaços coletivos, em que equipes de saúde compartilhem a elaboração de planos gerenciais e de projetos terapêuticos, depende ainda de uma ampla reformulação da mentalidade e da legislação do sistema de saúde. As políticas de humanização têm igualmente tentado ampliar o poder dos usuários no cotidiano dos serviços de saúde. Ressalta-se, nesse momento, que são tendências ainda não consolidadas e que o apoio matricial e mesmo o funcionamento de equipes de referência dependem de um importante grau de compartilhamento do poder entre distintos profissionais componentes de uma equipe e desses com outros especialistas.

A circulação de informações, os contatos interprofissionais e a preocupação em captar as várias dimensões do sujeito com problema de saúde têm dimensões bastante restritas no modelo tradicional de estruturação do poder em organizações de saúde. Não é fácil acordar-se sobre o que está ou não em discussão, ou seja, até onde vai o poder de influência, ou mesmo de deliberação conjunta, entre os distintos especialistas. A equipe de referência e o apoio matricial diminuem o peso da influência "paterna" na solução de conflitos, ou seja, as autoridades externas - chefes, leis e regras - são reinterpretadas na horizontalidade dos irmãos reunidos em uma fratria 29 . Por outro lado, há poucos serviços organizados em sistemas de co-gestão, com equipes e colegiados com poder de deliberação e com sistemas interdepartamentais e interequipes de construção de pactos de gestão.

Resumindo: o método do apoio matricial depende da existência de espaços coletivos, ou seja, do estabelecimento de algum grau de co-gestão ou de democracia institucional.

\section{Obstáculo subjetivo e cultural}

O trabalho interdisciplinar depende também de certa predisposição subjetiva para se lidar com a incerteza, para receber e fazer críticas e para tomada de decisão de modo compartilhado. É mister reconhecer que não é esse o padrão de subjetividade dominante em ambientes de con- 
corrência exacerbada, modo predominante de funcionamento das instituições contemporâneas ${ }^{30}$. Nesses casos, as pessoas tendem a cristalizar-se em identidades reativas, que as induzem a desconfiar do outro e a defender-se de modo paranóico da concorrência alheia. Por outro lado, é comum o profissional construir identidade e segurança, apegando-se à identidade de seu núcleo de especialidade, o que dificulta a abertura para a interação inevitável em espaços interdisciplinares.

Nesses ambientes, a descoberta de problemas ou de faltas costuma ser identificada à falha ou erro e ser utilizada para luta política ou em defesa de interesses particulares 31 . Não há cultura, entre gestores e entre equipes, sobre métodos para programar trabalho dialógico e interativo, criando instâncias de mediação, espaços protegidos e processos de contrato em que se estabeleçam metas e critérios para avaliação do trabalho.

Os profissionais habituaram-se a valorizar a autonomia profissional, julgando-a conforme o direito que teriam de deliberar sobre casos de modo isolado e definitivo. $\mathrm{O}$ apoio matricial promove encontro entre distintas perspectivas, obrigando os profissionais a comporem projetos terapêuticos com outras racionalidades e visões de mundo. Note-se que, em casos de impasse, e se o impasse se referir ao terapêutico, não há instâncias superiores para resolver o conflito. $\mathrm{O}$ gerente em saúde, em geral, tem pequena capacidade de interferir sobre conduta específica do especialista, cabendo aos envolvidos no conflito encontrar uma saída que não prejudique o usuário nem paralise o projeto terapêutico.

O conceito de projeto terapêutico tem se mostrado útil para mediar esse tipo de relação. Trata-se de uma discussão prospectiva de caso, em que, depois de uma avaliação de risco e de vulnerabilidade compartilhada, são acordados procedimentos a cargo de diversos membros da equipe. Ainda que seja possível uma descrição singela desse tipo de trabalho em grupo, não é simples, no cotidiano, estabelecer-se esse tipo de diálogo, com decisões e tarefas definidas de modo compartilhado.

\section{Obstáculo ético}

Se o método de trabalho com base em equipe de referência e apoio matricial busca definir de maneira precisa a responsabilidade sanitária, ao mesmo tempo, complica-se o tema da privacidade e do segredo sobre a história do paciente, da família ou de grupos comunitários. A utilização de prontuário único pela equipe interdisciplinar, a discussão de casos em equi- pe, toda essa circulação de informação, obriga a todas as profissões de saúde a repensarem o tema das relações entre eles e deles com os usuários. Que aspectos de uma história colhida em um atendimento individual, um médico ou uma psicóloga ou um enfermeiro podem registrar no prontuário ou comunicar aos demais membros da equipe ou do apoio? Observação que um agente de saúde recolhe durante uma visita familiar, como e em que grau divulgá-la a outros colegas de equipe? Cada profissional teria um registro particular e outro compartilhado com a equipe? Como lidar com o coletivo e com a circulação de informação, sem comprometer o direito à privacidade de cada caso ou de cada família?

\section{Obstáculo epistemológico}

A maioria das especialidades e profissões de saúde trabalha com um referencial sobre o processo saúde e doença restrito. Predominam os filiados à racionalidade biomédica, o que os leva a pensar e a agir segundo essa perspectiva restrita 32 . Outros tendentes a valorizar o social na explicação desse fenômeno também geram soluções restritas a essa linha de intervenção 33. O mesmo se pode observar entre aqueles adeptos de explicação subjetiva (desejo ou cognição) que pensam linhas de trabalho restritas a esses planos. O enfoque de clínica ampliada, ou clínica do sujeito, sugere maneiras para integrar essas perspectivas em um método de trabalho que reconheça a complexidade e variabilidade dos fatores e dos recursos envolvidos em cada caso específico, seja ele um problema individual ou coletivo. Pois bem, novamente o apoio matricial é um dispositivo importante para ampliação da clínica; ao mesmo tempo, para se trabalhar em uma perspectiva interdisciplinar, pressupõe-se algum grau de adesão a um paradigma que pense o processo saúde, doença e intervenção de modo mais complexo e dinâmico. 


\section{Resumo}

Os autores apresentam uma reconstrução teórico-conceitual da metodologia de gestão do trabalho em saúde baseada em equipes de referência e apoio matricial. Equipe de referência é um rearranjo organizacional que procura coincidir o poder de gestão com a equipe interdisciplinar. O apoio matricial sugere modificações entre as relações dos níveis hierárquicos em sistemas de saúde; nesse caso, o especialista integra-se organicamente a várias equipes que necessitam do seu trabalho especializado. Além da retaguarda assistencial, objetiva-se produzir um espaço em que ocorra intercâmbio sistemático de conhecimentos entre as várias especialidades e profissões. São apontados obstáculos estruturais, éticos, políticos, culturais, epistemológicos e subjetivos ao desenvolvimento desse tipo de trabalho integrado em saúde.

Gestão em Saúde; Metodologia; Epistemologia

\section{Referências}

1. Campos GWS. Equipes de referência e apoio especializado matricial: uma proposta de reorganização do trabalho em saúde. Ciênc Saúde Coletiva 1999; 4:393-404.

2. Prefeitura de Campinas. Saúde mental: apoio matricial ao Paidéia. Campinas: Secretaria Municipal de Saúde; 2001.

3. Prefeitura de Campinas. Paidéia - saúde da família, programa da Secretaria Municipal de Saúde. Campinas: Secretaria Municipal de Saúde; 2001.

4. Ministério da Saúde. Documento base para gestores e trabalhadores do SUS - cartilha da PNH. http://www.saude.gov.br (acessado em 14/ Set/2005).

5. Brasil. Portaria n. 1.935. Saúde mental no SUS: os centros de atenção psicossocial. Diário Oficial da União 2004; 16 set.

6. Ministério da Saúde. Guia prático do Programa Saúde da Família. http://www.saude.gov.br/bvs (acessado em 21/Set/2005).

7. Campos GWS. O anti-Taylor: sobre a invenção de um método para co-governar instituições de saúde produzindo liberdade e compromisso. Cad Saúde Pública 1998; 14:863-70.

8. Starfield B. Primary care: concept, evaluation and policy. New York: Oxford University Press; 1992.

9. Prefeitura de Campinas. Plano de saúde da Secretaria Municipal de Saúde. Campinas: Secretaria Municipal de Saúde; 2002.

10. Novaes HM. Ações integradas nos sistemas locais de saúde - SILOS. São Paulo: Biblioteca Pioneira de Administração e Negócios; 1990.

\section{Colaboradores}

Todos os autores participaram desde a revisão bibliográfica e análise documental até a redação final do artigo.
11. Motta FCP. Teoria geral da administração. São Paulo: Editora Livraria Pioneira; 1987.

12. Houaiss A, Villar MS. Dicionário da língua portuguesa. Rio de Janeiro: Editora Objetiva; 2004.

13. Campos GWS. Sobre la reforma de los modelos de atención: un modo mutante de hacer salud. In: Eibenschutz C, organizador. Política de saúde: o público e o privado. Rio de Janeiro: Editora Fiocruz; 1996. p. 293-314.

14. Campos GWS. Um método para análise e co-gestão de coletivos. São Paulo: Editora Hucitec; 2000.

15. Rivera FJU. Reflexões sobre a subjetividade na gestão a partir do paradigma da organização que aprende. Ciênc Saúde Coletiva 2001; 6:209-19.

16. Camargo Jr. KR. Biomedicina, saber \& ciência: uma abordagem crítica. São Paulo: Editora Hucitec; 2003.

17. Artmann E, Rivera FJU. A démarche strategique (gestão hospitalar estratégica): um instrumento de coordenação da prática hospitalar baseada nos custos de oportunidade e na solidariedade. Ciênc Saúde Coletiva 2003; 8:479-99.

18. Chiavenato I. Introdução à teoria geral da administração. 3a Ed. São Paulo: Editora McGraw-Hill; 1983.

19. Organização Pan-Americana da Saúde/Organização Mundial da Saúde. A transformação da gestão de hospitais na América Latina e Caribe. Brasília: Organização Pan-Americana da Saúde/Organização Mundial da Saúde; 2004.

20. Malik AM, Schiesari LMC. Qualidade na gestão local de serviços de saúde. São Paulo: Faculdade de Saúde Pública, Universidade de São Paulo; 1998. (Série Saúde \& Cidadania). 
21. Nogueira RP. A saúde pelo avesso. Natal: Editora Seminare; 2003.

22. Prochnow AG, Leite JL, Erdmann AL. Teoria interpretativa de Geertz e a gerência do cuidado: visualizando a prática social do enfermeiro. Rev Latinoam Enfermagem 2005; 13:583-90.

23. Schiesari LMC. Cenário de acreditação hospitalar no Brasil: evolução histórica e referências externas [Dissertação de Mestrado]. São Paulo: Faculdade de Saúde Pública, Universidade de São Paulo; 1999.

24. Gurgel Jr. GD, Vieira MMF. Qualidade total e administração hospitalar: explorando disjunções conceituais. Ciênc Saúde Coletiva 2002; 7:325-34.

25. Reis COO. Desigualdade no acesso aos serviços de saúde. In: Negri B, Giovanni G, organizadores. Brasil: radiografia da saúde. Campinas: Núcleo de Estudos de Política Pública, Universidade Estadual de Campinas; 2001. p. 579-86.

26. Vasconcelos CM. Paradoxos da mudança no SUS [Tese de Doutorado]. Campinas: Faculdade de Ciências Médicas, Universidade Estadual de Campinas; 2005.
27. Starfield B. Atenção primária: equilíbrio entre necessidades de saúde, serviços e tecnologia. Brasília: Organização das Nações Unidas para a Educação, a Ciência e a Cultura/Ministério da Saúde; 2002.

28. Cortes SMV. Construindo a possibilidade da participação dos usuários: conselhos e conferências no Sistema Único de Saúde. Sociologias 2002; (7):18-48.

29. Campos RO. O encontro trabalhador-usuário na atenção à saúde: uma contribuição da narrativa psicanalítica ao tema do sujeito. Ciênc Saúde Coletiva 2005 ; 10:573-83.

30. Jameson F. Pós-modernismo: a lógica cultural do capitalismo tardio. São Paulo: Editora Ática; 1996.

31. Saupe R, Certulo LR, Wendhausen AL, Benito GA. Competências dos profissionais da saúde para o trabalho interdisciplinar. Interface Comun Saúde Educ 2005; 9:521-36.

32. Luz MT. Natural, racional, social: razão médica e racionalidade científica moderna. São Paulo: Editora Hucitec; 2004.

33. Carvalho AI. Da saúde pública às políticas saudáveis - saúde e cidadania na pós-modernidade. Ciênc Saúde Coletiva 1996; 1:104-21.

Recebido em 31/Out/2005

Versão final reapresentada em 28/Abr/2006

Aprovado em 20/Jun/2006 